\section{Smart wheel chair}

\section{Sarmad Hameed*, Muhammad Hamza Shoukat, Abdur Rafay Khan and Khwaja Mobeen Haroon}

Department of Mechatronics Engineering, Shaheed Zulfiqar Ali Bhutto Institute of Science and Technology (SZABIST), University in Karachi, Pakistan
Received: 10 May, 2021

Accepted: 20 May, 2021

Published: 22 May, 2021

*Corresponding author: Sarmad Hameed, Department of Mechatronics Engineering, Shaheed Zulfiqar Ali Bhutto Institute of Science and Technology (SZABIST), University in Karachi, Pakistan,

E-mail: Sarmad.hameed@szabist.edu.pk

Keywords: Wheel chair; Mobile application; Hand gesture; Voice commands

https://www.peertechzpublications.com

\title{
Abstract
}

While degrading mobility, one of the major concerns affecting the independent ability of elderly / disabled people to live. Mobility assistive technologies are now being built to uplift people's living conditions. However, improvements are required to existing mobility assistive devices. This paper explores designing and building a smart wheel chair with several control interfaces. A version of the smart wheelchair device was built based on a currently accessible traditional wheelchair on the market, with the introduction of similar electrical and mechanical developments. To improve user involvement, the system includes speech and gesture-control interfaces as addition to the Mobile Application for controlling the Wheel Chair. Particulars are presented regarding the mechanical design, the smart wheelchair's electrical and control system. Experiments were carried out to verify the functionality of the smart wheelchair that was developed. Furthermore addition, a user study evaluated the user preferences between the different controlling interfaces, and the results are presented.

\section{Introduction}

The main objective of this paper is to control a wheel using hand gesture by the means of smartphones, for this purpose android application is created. An efficient system will provide a user with good outcome so for that android platform is chosen because it provides open tools for this operation. Motor drivers are controlled via Arduino controller. In this configuration Arduino app is connected via android application using master-slave. HC-005 Bluetooth module is used which is slave and smartphone which is master[1].

In this paper the testing is done for the wheel chair movement using built in voice, for this a user voice is recorded for the movements forward, backward, left, right and stop. There are two main aspects which include voice system accuracy and other is wheel chair velocity. The voice is recorded in a quite environment so that noise can be reduced and then user voice is recorded. If the user words are match with the frequency of the words which are stored in the system then it will according to it[2].

Automated Smart Wheelchair is designed and fabricated for disabled persons which is operated with android application. This app can be download and can be used as a controller for the wheelchair. Smartphone built gyroscope feature will help the user to tilt the phone and according to this the wheelchair will operate for example if user tilt 30 degree to the right then wheelchair will turn right and for the forward motion the phone will be tilt from the front side. For obstacle avoidance IR sensor is used if an emergency occurs the Wheelchair will stop[3].

In this research paper the authors discuss about modifying a regular non-motorized wheelchair for patients with weak upper body. The patient is also not capable of understanding the complex instruction of a powered wheelchair and therefore the solution suggested in this paper is voice control application. The wheelchair has DC motors controlled by a microcontrollerbased control system via the motor driver circuit. The control circuit is connected to an android phone with the application for the task. The user speaks into the phone and the commanded is conveyed to the microcontroller circuit over a Wi-Fi network. Ultrasonic sensors are used in the wheelchair to avoid obstacles [4].

The research paper is about upgrading a powered wheelchair to serve larger number of disabled persons. This is achieved by combining DC motor, motor drivers and microcontroller system. The android based control circuit controls the direction of the wheel chair. Bluetooth communication is used to communicate with the control circuit using an existing android phone. The 
android application used in this project is downloaded into the phone of the user which reduces the cost of the wheelchair. The four directions of motion are forward, reverse, right and left. The communication between the phone and the control circuit is wireless [5].

The wheel chair can be communicated via joy stick in which the user will control the wheel chair using built in parameters for forward, backward, left and right command. Also, the speed of the wheel can also be adjusted through this joystick. The purpose of this feature is to allow the user to exert less effort and more safety [6].

A new complex feature which is known as Head controlled wheel chair uses V frame and SPDT switch. SPDT switch or single pole double throw switch and 4 SPDT type relays of 12 $\mathrm{V}$ and $10 \mathrm{Amps}$ are used for directions left, right, forward and reverse. These switches are attached with the $\mathrm{V}$-frame and will help the user to move in the desired position [7].

A smart wheelchair, as described earlier in this article, may be identified as a mobile robot with seats or as a uniquely modified powered wheelchair fitted with a control system and variant sensors. But smart navigation approaches are important smart chair features. In 2010 Christina Tsalicoglou and Xavier Perrin performed a study on mobility aids for people with disabilities [8]. Many initiatives are researching how a smart wheelchair can be of full assistance to its operator according to this report. Methods of navigation are classified into three groups according to help rate. The three key types are: mutual control, semi-autonomous control and entirely decentralized power. The benefit of autonomous and semi-autonomous systems is that just once in a while the consumer has to send a order and can relax until the order is provided, as the control is automatic. Shared ownership allows the user more freedom, since the user may manage the flow and schedule the road. The smart chair only offers rescue or mitigating measures such as stopping accidents, removing barriers and following partitions [9].

It's clear from the names "semi-autonomous control" and "autonomous control" that machine assistance is increasing. Therefore, wheelchairs are more interested in route planning, in addition to prevention of accidents, avoiding obstacles and approaching walls. Semi-autonomous systems wait for user commands that provide a local target for the short term. The wheelchair then starts moving until the navigation system alerts an external flag that the order has been completed. Semiautonomous devices could be useful in cases such as people with visual impairments. They aid them with the versatility benefit of freedom, as in the "Support Star" system [10]. The "Support Star" role may be triggered when the consumer encounters an unexpected situation. It enables a remote user to use augmented reality technology to offer valuable steering guidance or to explicitly transmit orders to the wheelchair [8]

The consumer specifies the final intended destination in autonomous system and the wheelchair mechanism assumes direct care of travel from the current position to the target destination. Therefore, autonomous systems require techniques for mapping and location tracking. Accordingly, they typically favoured service in well-defined settings. To ensure navigation safety and robustness, researchers suggested having the wheelchair ride along a reference marker structured in a lattice shape as in Hiroo Wakaumi's and Tsuneo Tsukagoshi 's patent number US5002145 A [11].

Synthesized landmark maps for total localization of an outdoor smart wheelchair device are used in [12] to render the wheelchair accessible in urban area. First move was to create a three-dimensional map for the project. A vehicle with high precision inertial / GPS systems in combination with Light Detection and Ranging (LIDAR) systems acquires data for the route. The resulting map data are then synthesized priority to define stable, distinctive features in localization for use as landmarks. The machine was able to hold outdoor predictions of precise, global pose across approximately $1 \mathrm{~km}$ of roads [9].

In autonomous and semi-autonomous wheelchair systems more sophisticated solutions and sensors may be available. For instance, a panoramic camera with 360-degree field of view and sonar sensors are added to monitor a target individual in [13]. The goal person shall be identified from a computer by the wheelchair owner. The controls, the processing resources and the software required to incorporate control patterns and user interfaces (touch screen, voice commands) have been built as additional components and incorporated with the wheelchair. Another illustration is an unconsciously shifting activity between indoor and outdoor environments (for illustration speed or hazard threshold limits) [11].

A number of sensors may be regarded as guidance instruments with add-ons. Obstacle avoidance devices utilize sonars, infrared (IR) or LIDAR sensors to analyze the natural environment [13-15]. Sonar and IR sensors are widely used since they are lightweight, cheap and well known. With laser range finders (LRFs), which have $180^{\circ}, 2 \mathrm{D}$ scanning within the obstacle layer, the precision of 30 obstacle detection is improved. An example of using LRF in smart wheelchairs is [16].

Recognition trends and computer vision algorithms make cameras one of the main add-ons [16]. For instance on $\mathrm{T}$. Utilizing stereoscopic cameras by H.Nguyen et al. Left and right photos are taken from wheelchair fixed cameras The optimum variance is measured using a correlation formula named the Number of Absolute Disparities (SAD). The map is built from this difference to be used to provide this device with an efficient obstacle avoidance technique [15].

Autonomous wheel chair is also the most useful technology. In this technology three main features which includes modeling, calibration and epipolar geometry of cameras is used. Using SAD (sum of absolute differences) stereo disparity map is build and according to this map the robot will detect the obstacles and performance will be made. Using geometric projection approach this disparity map will be generated onto the 3D map. A 2-D map will be generated for real time processing [17].

The add-on unit solution offers versatility in sensor, controller, and input system settings, depending on 
the requirements of each particular customer. It makes adjustment of the procedure due to the shifts in the world or the improvement in the condition of the patient. Particularly for children it is satisfied because their bodies are continually growing[18].

Any essential add-ons can involve the tracking systems for patients. For example, the authors describe a framework for the control of cardio-respiratory and physical life. The paper discusses utilizing frequency modulated continuous wave (FMCW) and Doppler radar sensors mounted in a handheld wheelchair to assess the wheelchair user's heart and respiratory functions and physical exercise. Information is then transmitted to an Android tablet computer to be processed using Bluetooth communication protocol [19].

Alert systems are major add-ons, too. For example, a device named "BotBeep" is used for rearward protection in wheelchairs. The rear of a wheelchair is sometimes in the blind spot of a wheelchair user. Thus, the BotBeep mechanism alerts the patient of shifts in elevation behind the wheelchair that lead to gaps, steep slopes and staircases. Therefore, Bot Beep decreases the chance of slipping and rolling over. Using picture processing method, Smartphone is used as a computational system [20].

Research in smart wheelchairs in the field of robotics and artificial intelligence can be seen as prominent. The smart wheelchairs sold are not readily identified, however. The hunt for the word "wheelchair" on e-commerce websites provides a vast range of manual wheelchairs, only a few mechanical wheelchairs with standard joysticks and a few smart wheelchairs. One of the foreign e-commerce portals [21].

It's worth noting that not all the 10 smart wheelchairs identified in the previous review apply to this paper's concept of smart wheelchair. Most of them are smart in design, or because of fast folding, stair ascending, standing feature and other related facilities the producers name them smart. We find that only Smile Smart Technology Ltd sells actual, smart wheelchairs in the UK. This is because the technology's robustness and reliability is not yet assured in several researches to 100 percent. In the other side, while effective autonomous wheelchair technology is available, the decision to use it or not depends on the nature of the injury, the general morale and attitude of the person towards his or her condition and the technology price [22]. In other terms, the most critical considerations in the commercialization of smart technology are expense, ease of use and personalization.

\section{Methodology}

The device architecture consists of an Arduino Uno microcontroller which serves as the Wheel Chair bot 's brain, motor driver circuitry which is responsible for controlling the 24-volt DC motors attached to the wheels, and a remote controller which controls the bot 's motion. The microcontroller communicates through transmitter and receiver. The hardware is designed in such a way that the wheel chair easily moves on a plane surface. The two DC motors provide necessary torque required to move flawlessly with $80 \mathrm{~kg}$ patient. The motors are synced such that they both rotate at equal rpm to move the wheelchair in a straight line. To move the wheelchair to the right or left their respective motor rotates the wheel and the direction is easily and safely changed by the user. The motors are powered by a single DC LINO 12 -volt $26 \mathrm{Ah}$ rechargeable battery. The battery also provides necessary power to the electronics of the project. A single Arduino mega is the brain of the smart wheel chair. It connects the Bluetooth, the motor drive circuits, the MPU sensor and the buck boost circuits. The shaft of the motor is connected to the wheels via a strong chain sprocket mechanism. This mechanism was selected for its durability and ease of maintenance Figure 1.

\section{Principle of operation}

The implementation of the smart wheel chair was broken into two halves, hardware and software. The hardware consists of the wheelchair itself and DC motors and battery. The software part is composed of programing and PCB designing. The programming was done in Arduino IDE while circuit designing and testing was performed using Fritzing open source program.

The hardware is designed in such a way that the wheel chair easily moves on a plane surface. The two DC motors provide necessary torque required to move flawlessly with $80 \mathrm{~kg}$ patient. The motors are synced such that they both rotate at equal rpm to move the wheelchair in a straight line. To move the wheelchair to the right or left their respective motor rotates the wheel and the direction is easily and safely changed by the user. The motors are powered by a single DC LINO 12-volt 26Ah rechargeable battery. The battery also provides necessary power to the electronics of the project. A single Arduino mega is the brain of the smart wheel chair. It connects the Bluetooth, the motor drive circuits, the MPU sensor and the buck boost circuits. The shaft of the motor is connected to the wheels via a strong chain sprocket mechanism. This mechanism was selected for its durability and ease of maintenance.

\section{a. Gear box}

Gearbox is used to bear more wight with less effort. The gearbox of $24: 1$ is used because of the max torque required to move $130 \mathrm{Kg}$ weight of person in an ideal condition is $60.6 \mathrm{Nm}$ from the calculations. The gearbox will enhance the motor torque which is $3.5 \mathrm{Nm}$ to $84 \mathrm{Nm}$ (3.5 x 24). Gearbox was

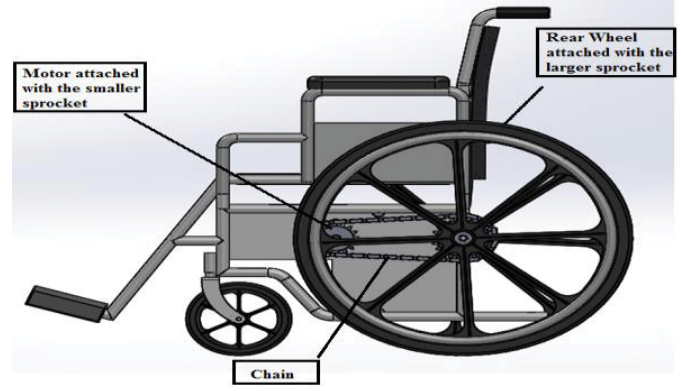

Figure 1: Assembly picture of Smart Wheel Chair. 
inserted after all the calculations are made so that the value of motor transmitted torque should be in the range Figure 2 .

\section{b. Motor}

Motor which we have selected for the wheel chair is $24 \mathrm{~V} \mathrm{DC}$ Geared. The operating current for the motor is 3 Amperes while maximum current is about 20 Amperes. The 3600 RPM motor has a rated power of 50 Watts. Motors a are directly coupled with the gear box of $24: 1$ and is further coupled with a smaller sprocket Figure 3.

\section{c. Chain sprocket}

Chain sprocket mechanism is used to reduce the Rear Wheel torque. The sprocket has a gear ratio of 3:1 which will reduce the rear wheel torque by a factor of 3 . Two chains and 4 sprockets are used for the driving mechanism. Smaller sprocket has 11 number of teethes and larger sprocket have 32 number of teeth. Our concern is with the smaller sprocket so motor gearbox is coupled with the smaller sprocket Figure 4.

\section{d. Battery}

A $12 \mathrm{~V}$ battery is used to drive the motor directly and an Arduino controller with the help of buck regulator. Motor can be operated on $12 \mathrm{~V}$ such that rpm would be reduced to its halved value. 26 Ah battery would provide 26 amperes max to flow for an hour such that for the motor which is operating at maximum condition 20 ampere would take 20 amperes of current for an hour Figure 5.

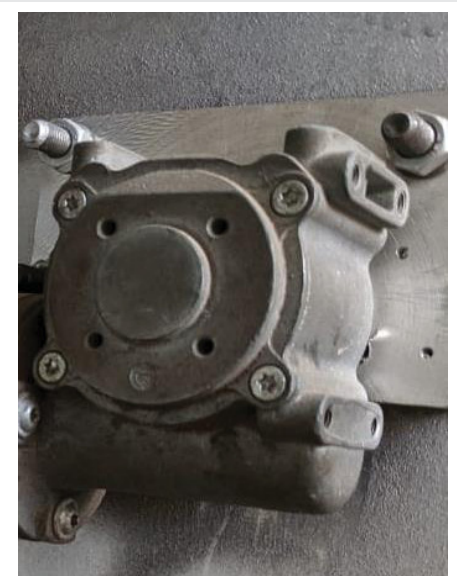

Figure 2: Gear Box 24:1

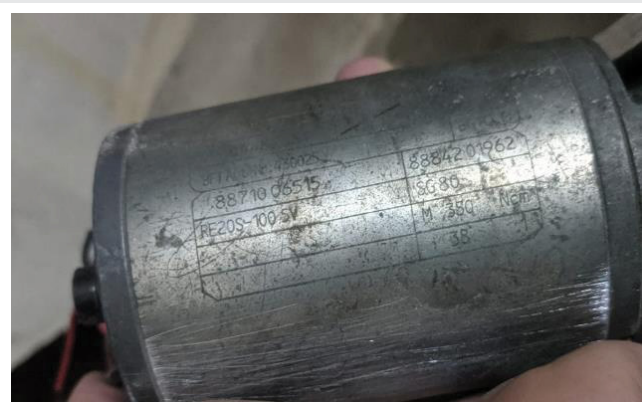

Figure 3: Motor 24Volts

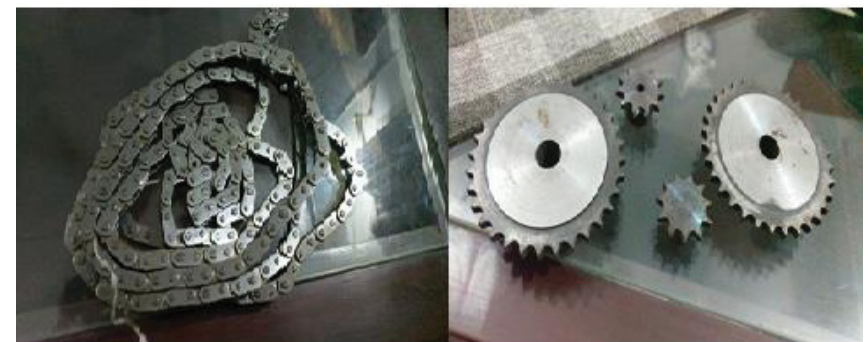

Figure 4: Chain Sprocket.

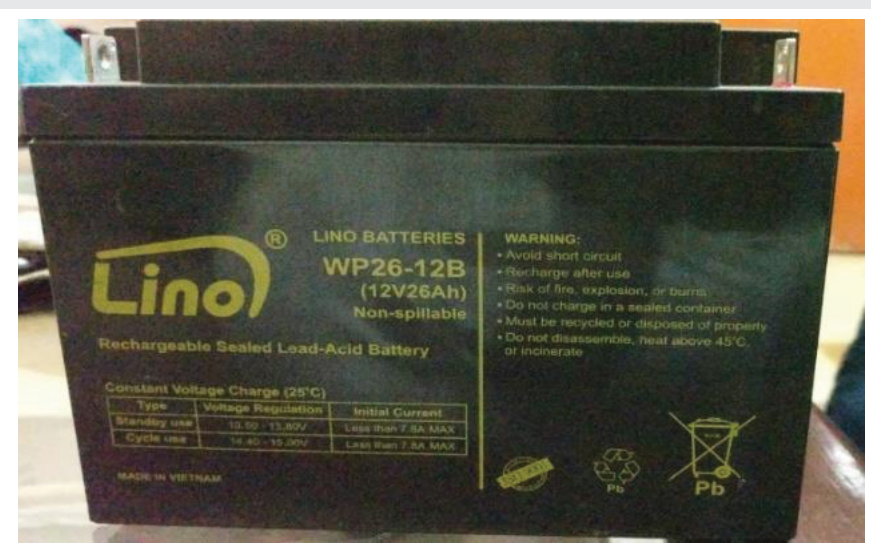

Figure 5: LINO Battery $12 \mathrm{~V}$ - 26Ah.

\section{e. Motor with gear box}

A gearbox, better known as a gear reducer or velocity reducer, is a series of gears that may be attached to a motor to significantly decrease speed and/or improve torque. Torque is strictly proportional to the displacement of a motor (length of square times diameter). That means that the same amount of output torque could be provided by a very large motor and a relatively small gearbox Figure 6 .

\section{f. Gear box connecting plate}

Gearbox is used for the purpose of enhancing tire performance in robotic vehicles. That goal is reached when the gearbox and the tires are matched together correctly. Four gearbox connecting plates, each for each tire, of extruded star shape at the center are used to obtain this factor, which are attached to the tires to fit them with the gearbox. This improves tire performance as well as driving mechanism Figure 7 .

\section{g. Sonar sensor}

Sonar sensor is used for obstacle avoidance, this sensor will help in detection of any object. If the object appear it will stop the wheel chair Figure 8.

\section{h. MPU sensor 5060}

MPU sensors are basically Inertia Measurement unit sensors that are usually use for self-balancing. It communicates with Arduino and helps us get the desired position of the object Figure 9.

\section{i. System flow}

System flowchart's shows the software and hardware part 
in order to deliver a complete final product of a Smart Wheel chair system. This flow chart provides a basic conceptual view that how mobile is synchronized with the Bluetooth and how Arduino Mega is interfacing with the Motors and boost circuit. Motors are interfacing via motor drivers with the Arduino controller Figure 10.

\section{j. Analysis}

The working mechanism of the wheelchair is both simple and effective. Firstly, using a control device, signal is sent to the Bluetooth module connected to the Arduino mega board. This interprets the signal to switch on/off the motor drive circuits. Each motor has its own dedicated drive circuit. The current from the motor drive goes into the motor which in turn rotates the wheel it is connected to via chain sprocket mechanism.

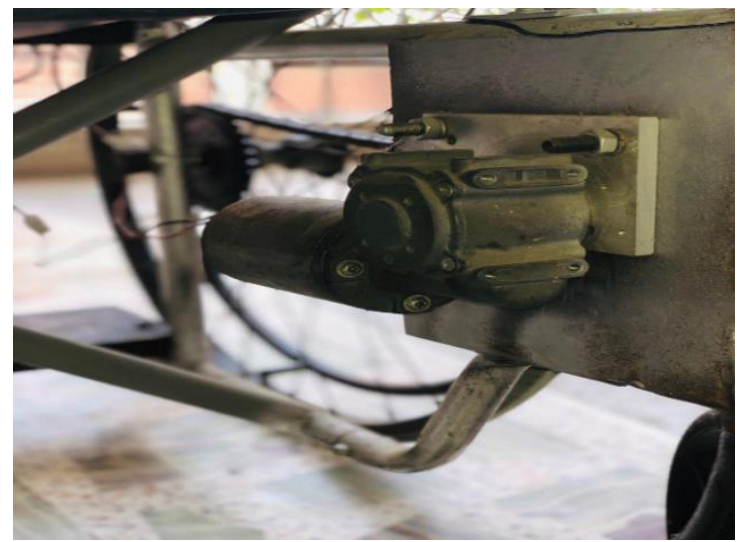

Figure 6: Motor coupled with gear box.

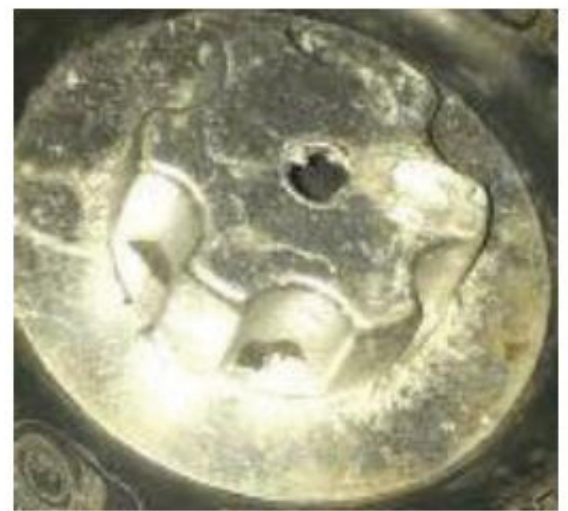

Figure 7: Connecting Plate.

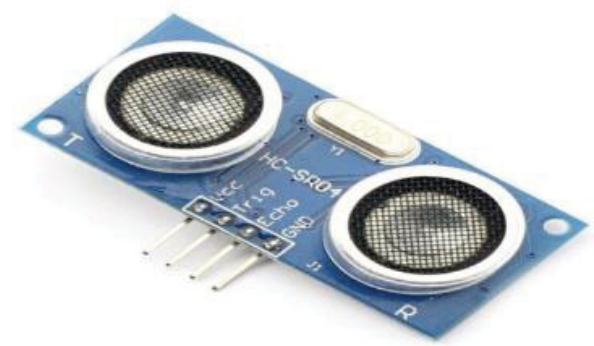

Figure 8: Sonar Sensor.

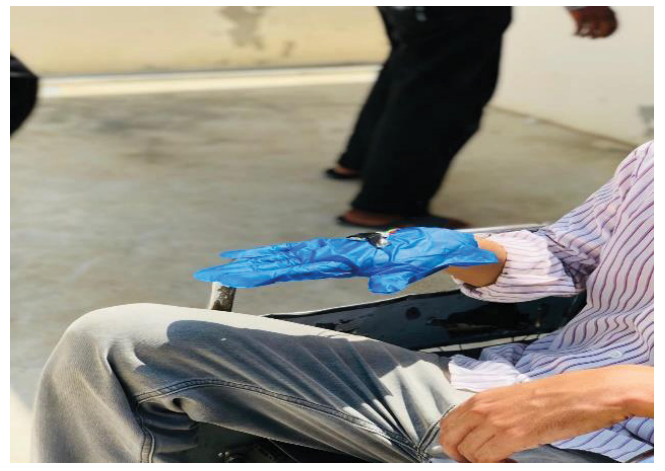

Figure 9: MPU sensor 5060

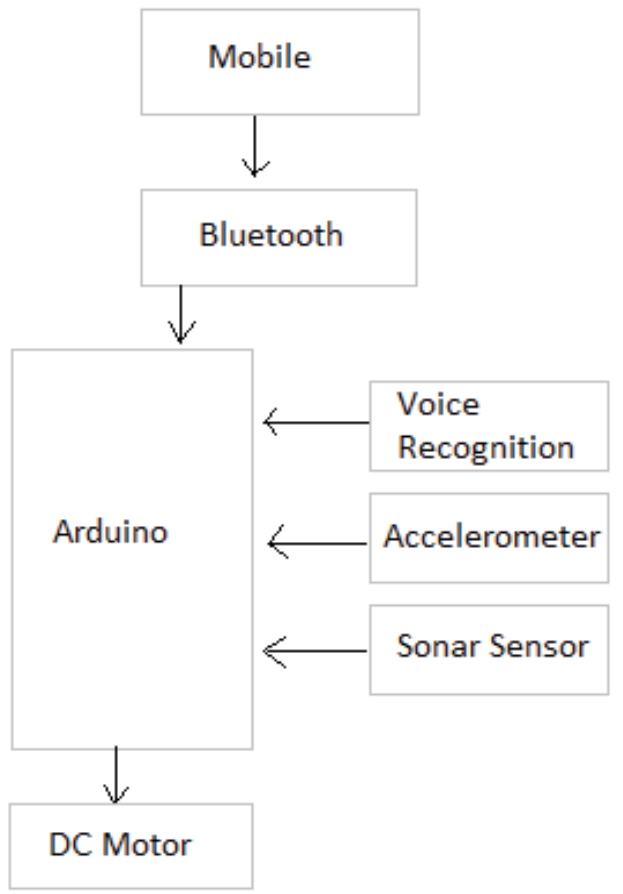

Figure 10: Process flow of the overall system.

This same process is also applicable when using MPU as the control device. The signals are directly provided to the Arduino board without the need of Bluetooth module. The MPU detects hand movement of the patient. Each specific gesture corresponds to a specific movement of the wheelchair Figure 11.

\section{Torque required for the motor}

$$
\begin{aligned}
& f_{R}=\text { Frictional Force } \\
& F_{M a x}=\text { Maximum Force } \\
& \mathrm{N}=\text { Normal Contact Force } \\
& \mathrm{a}=\text { acceleration } \\
& \mathrm{u}=\text { coefficient of friction } \\
& \mathrm{m}=\text { Mass of the person } \\
& \mathrm{g}=\text { gravitational acceleration }\left(9.8 \mathrm{~m} / \mathrm{s}^{2}\right)
\end{aligned}
$$


External Weight $=$ Weight of battery + weight of electronic box + weight of chair + weight of motors

External Weight $=7.2+0.7+21.5+3$

External Weight $=32.4 \mathrm{~kg}$

For weight $=85 \mathrm{Kg}$

Total Weight $=$ Weight of person + External weight

Total Weight $=85+32.4$

Total Weight $=117.4 \mathrm{~kg}$

Since there are two motors attached so weight exerted by each motor will be the halve value of the total weight since there are two main reaction forces on Rear Wheel. The caster wheel will have very low impact on the wheel chair since they are for supporting the wheel chair so the reaction forces of those caster wheel are not making into consideration Figure 12.

So, Weight exerted by motor $1=117.4 / 2$

Weight exerted by motor $1=58.7 \mathrm{~kg}$

Now Maximum force exrted by the wheel chair will be calculated

$$
F_{\text {Max }} f_{R}=\mathrm{m} \times \mathrm{a}(1)
$$

Now, for the ideal condition normal wheel chair accelerates at $4.0 \mathrm{~m} / \mathrm{s}^{2}$ and coefficient of friction $(\mathrm{u})$ for rough surface is 0.3. By these values Maximum force is calculated.

$$
\begin{aligned}
& \mathrm{N}=\mathrm{m} \times \mathrm{g}(2) \\
& f_{R}=\mathrm{u} . \mathrm{N}(3) \\
& f_{R}=0.3 \times 58.7 \times 9.8 \\
& F_{M a x}=f_{R}+\mathrm{m} \times \mathrm{a}(4) \\
& F_{M a x}=172.5+(58.7 \times 4.27)
\end{aligned}
$$

$\mathrm{FMax}=423.2 \mathrm{~N}$

Wheel Diameter $=0.6 \mathrm{~m}$

Torque $=F_{\text {Maxx }}$ Diameter $/ 2(5)$

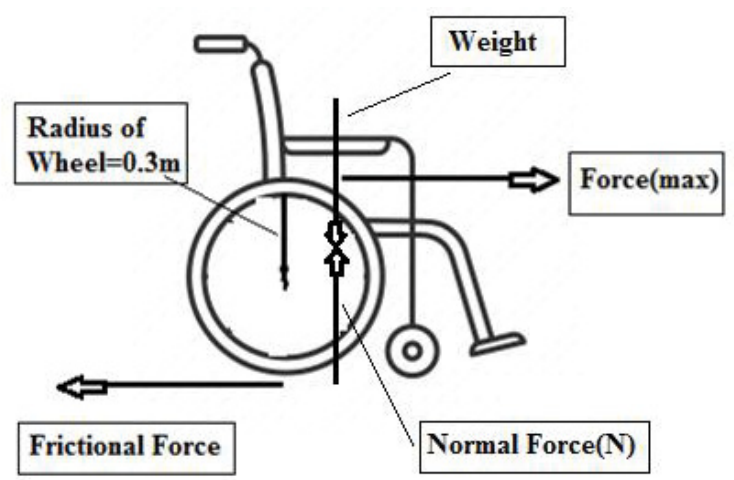

Figure 11: Free Body Diagram (Wheel Chair).

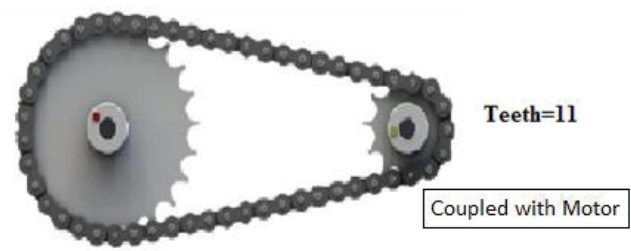

Figure 12: Chain Sprocket.

Torque $=423.2 \times 0.3$

Torque $=126.9 \mathrm{Nm}$.

Gear Ratio= Driven Sprocket teeth/drive sprocket teeth (6)

Gear Ratio $=32 / 22=2.9$

Torque of Motor= Torque of Rear wheel/Gear ratio (7)

Torque $=126.9 \mathrm{Nm} . / 2.9$

New Torque $=43.7 \mathrm{Nm}$

\section{Results}

The results have been carried out for weight $70 \mathrm{Kg}$ to 130 $\mathrm{Kg}$. Total weight is equal to the sum of external weight which includes batteries, motors and electronic equipment. Then this weight is halved so that whole weight which was acting on the wheel chair is distributed on the rear wheels and from the Newton 2nd law equation. Rear Wheel torque is then calculated which is equal to the product of maximum force and the distance from the axis of rotation which is 0.3 meters Table 1.

The key aspect of wheelchair system is finding its speed. Whilst the Speech operated wheelchair moves in a straight line, for velocity is noted in the distance and time. The wheel chair velocity needs to be tested on two conditions. In unloaded condition the speed is measured first. The wheelchair was designed to travel in a straight line, and a speed of $0.8 \mathrm{~m} / \mathrm{s}$ is observed. Second, the wheelchair was allowed to carry the load with $15 \mathrm{~kg}$ loads, and the velocity was found to be $0.76 \mathrm{~m} /$ s. A person weighing $78 \mathrm{~kg}$ finally sat in the wheelchair. This required the voice operated wheelchair to travel in a straight line. The wheel chair velocity with this charge is $0.72 \mathrm{~m} / \mathrm{s}$. The voice recognition system will first be tested with one user in a quiet room. All words are well recognized. First, we will look at someone else's machine that has not been trained on it. In this case, almost 5 percent errors occurred, for example words such as "true" are known as "write." This was because they heard a different pronunciation before. However, the acquirer had enough examples after the user spoke the word several times and correctly determined which words the user was speaking Table 2.

From the above calculations both the motors are now synchronized as the motor 1 and motor 2 both has the value of 1980 RPM. Buck regulator is used to provide $18 \mathrm{~V}$ for motor 1 and $20 \mathrm{~V}$ for motor 2 to make them synchronize, whereas battery has the output voltage of 24 . The motor RPM was checked with the help of solid works software by which we achieved a torque 
value of approximate $43 \mathrm{Nm}$ which is almost same with the ideal calculation Figure 13.

\section{Conclusion}

The key aspect of wheelchair system is finding its speed. Whilst the Speech operated wheelchair moves in a straight line, for velocity is noted in the distance and time. The wheel chair velocity needs to be tested on two conditions. In unloaded condition the speed is measured first. The wheelchair was designed to travel in a straight line, and a speed of $0.8 \mathrm{~m} / \mathrm{s}$ is observed. Second, the wheelchair was allowed to carry the load with $15 \mathrm{~kg}$ loads, and the velocity was found to be $0.76 \mathrm{~m} /$ s. A person weighing $78 \mathrm{~kg}$ finally sat in the wheelchair. This required the voice operated wheelchair to travel in a straight line. The wheel chair velocity with this charge is $0.72 \mathrm{~m} / \mathrm{s}$. The voice recognition system will first be tested with one user in a quiet room. All words are well recognized. First, we will look at someone else's machine that has not been trained on it. In this case, almost 5 percent errors occurred, for example words such

Table 1: Torque Calculations.

\begin{tabular}{|c|c|c|}
\hline Weight of Person $(\mathbf{k g})$ & $\begin{array}{c}\text { Rear Wheel Torque } \\
(\mathbf{N m})\end{array}$ & Motor Torque (Nm) \\
\hline 102.4 & 110.8 & 38.2 \\
\hline 112.4 & 121.7 & 41.9 \\
\hline 117.4 & 127.1 & $43.8 \mathrm{cc}$ \\
\hline 122.4 & 132.5 & 45.6 \\
\hline 132.4 & 143.4 & 49.4 \\
\hline 142.4 & 154.2 & 53.2 \\
\hline 152.4 & 165.1 & 56.9 \\
\hline 162.4 & 175.9 & 60.6 \\
\hline
\end{tabular}

Table 2: Torque exerted by each Motor.

\begin{tabular}{|c|c|c|c|c|}
\hline $\begin{array}{c}\text { Weight of } \\
\text { person } \mathbf{( k g )}\end{array}$ & $\begin{array}{c}\text { Total Weight } \\
\mathbf{( k g})\end{array}$ & $\begin{array}{c}\text { Weight Exerted by } \\
\text { Motor1 } \mathbf{( k g})\end{array}$ & Force $_{\text {MAx }}(\mathbf{N})$ & $\begin{array}{c}\text { Rear Wheel } \\
\text { Torque } \\
(\mathbf{N m})\end{array}$ \\
\hline 70 & 102.4 & 51.2 & 369.6 & 110.8 \\
\hline 80 & 112.4 & 56.2 & 405.7 & 121.7 \\
\hline 85 & 117.4 & 58.7 & 423.8 & 127.1 \\
\hline 90 & 122.4 & 61.2 & 441.8 & 132.5 \\
\hline 100 & 132.4 & 66.2 & 477.9 & 143.4 \\
\hline 110 & 142.4 & 71.2 & 514.1 & 154.2 \\
\hline 120 & 152.4 & 76.2 & 550.2 & 165.1 \\
\hline 130 & 162.4 & 81.2 & 586.3 & 175.9 \\
\hline
\end{tabular}

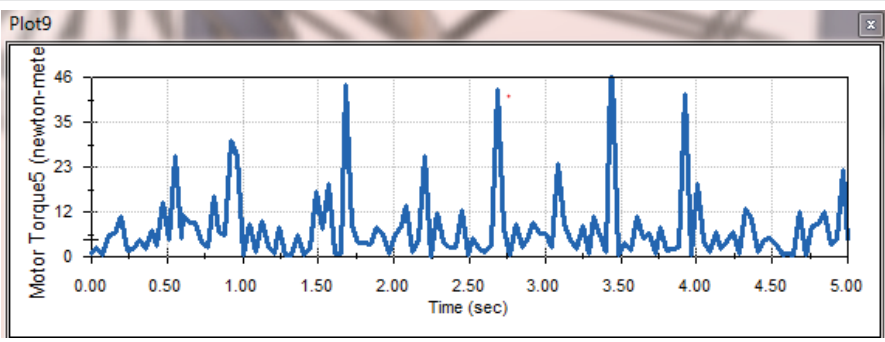

Figure 13: Motor Torque Vs Time. as "true" are known as "write." This was because they heard a different pronunciation before. However, the acquirer had enough examples after the user spoke the word several times and correctly determined which words the user was speaking.

Manufacturers and researchers face many challenges that need to be resolved in order to render smart wheelchair a market success and be commonly used. Cost versus accuracy is one common principal issue. Advanced sensors can help overcome this problem. There are no smart wheelchairs accessible that can often be used for certain types of disabilities. Smart wheelchairs should also be able to monitor and respond to the patient's condition. Currently, smart wheelchairs can be easily used in indoor environments but require a safety check for an outdoor environment.

A motorized wheelchair with smartphone device function, hand movement, or speech recognition was successfully developed and introduced. Overall loss included Rs.60000 PKR with whccceelchair prices. The speech recognition program has performed with most of the commands (over 95 per cent). It was not only understood by the machine that a phrase was not adequately vocalized. However, in this case the Smartphone Device may also be used as a backup evidence. Users have stated that they were pleased with the overall plan. Further research is required to help classify the tiny artifacts.

\section{References}

1. Jha P, Khurana P (2016) Hand Gesture Controlled Wheelchair. Int J Sci Technol Res 9: 243-249. Link: https://bit.ly/3ozM3tw

2. Clark JA, Roemer RB (1977) Voice controlled wheelchair. Arch Phys Med Rehabil 58: 169-175. Link: https://bit.ly/3ywjAcz

3. Ebrahimi A, Kazemi A, Ebrahimi A (2016) Wheelchair Design and Its Influence on Physical Activity and Quality of Life Among Disabled Individuals. Iran Rehabil J 14. Link: https://bit.ly/3vkZCjj

4. Mazo M, Rodríguez JF, Lázaro JL, Ureña J, Carlos Garcia Garcia J, et al. (1995) Wheelchair for physically disabled people with voice, ultrasonic and infrared sensor control. Auton Robots 2: 203-224. Link: https://bit.ly/3ozrEF5

5. Yao F (2007) Measurement and modeling of wheelchair propulsion ability for people with spinal cord injury. Link: https://bit.ly/2T3LJHL

6. Amundson JS, Amundson SG (1991) A joystick controlled wheelchair. Biomed Sci Instrum 27: 131-133. Link: https://bit.ly/3yvLYvk

7. Pajkanović A, Dokić B (2013) Wheelchair control by head motion. Serbian Electr Eng 10: 135-151. Link: https://bit.ly/3v9PMAr

8. Cooper RA (2012) Wheelchair research progress, perspectives, and transformation. J Rehabil Res Dev 49: 1-5. Link: https://bit.ly/3v9CAvA

9. Philips J, Millán J, Vanacker G, Lew E, Galán F, et al. (2007) Adaptive shared control of a brain-actuated simulated wheelchair," in 2007 IEEE 10th International Conference on Rehabilitation Robotics 408-414. Link: https://bit.ly/340yCcN

10. Braga RA, Petry M, Moreira AP, Reis LP (2009) Concept and design of the intellwheels platform for developing intelligent wheelchairs. Informatics in control, automation and robotics. 191-203. Link: https://bit.ly/3v9QzRV

11. Uchiyama H, Deligiannidis L, Potter WD, Wimpey WJ, et al. (2005) A semiautonomous wheelchair with HelpStar. in International Conference on Industrial, Engineering and Other Applications of Applied Intelligent Systems 809-818. Link: https://bit.ly/3oEWufA 
12. Gao C, Sands M, Spletzer JR (2010) Towards autonomous wheelchair systems in urban environments. Field and service robotics 13-23. Link: https://bit.ly/2T83829

13. Argyros A, Georgiadis P, Trahanias P, Tsakiris D (2002) Semi-autonomous navigation of a robotic wheelchair. J Intell Robot Syst 34: 315-329. Link: https://bit.ly/3ytK1Qb

14. Yanco HA (1998) Wheelesley: A robotic wheelchair system: Indoor navigation and user interface. Assistive technology and artificial intelligence 256-268. Link: https://bit.ly/3f8SmBn

15. Bruce A (2021) "Title: Features of the Best Manual Wheelchair. Monhonal, Link: https://bit.ly/3hJJ05I

16. Nguyen AV, Nguyen LB, Su S, Nguyen HT (2013) Shared control strategies for human-machine interface in an intelligent wheelchair. Annu Int Conf IEEE Eng Med Biol Soc 3638-3641. Link: https://bit.ly/3fEOjNK

17. Xavier J, Abreu PH, Reis LP, Petry M (2011) Location and automatic trajectory calculation of mobile objects using radio frequency identification. in 6th Iberian Conference on Information Systems and Technologies (CISTI 2011). 1-6. Link: https://bit.ly/3wk1AjV
18. Khadilkar SU, Wagdarikar N (2015) Android phone controlled voice, gesture and touch screen operated smart wheelchair. in 2015 International Conference on Pervasive Computing (ICPC). 1-4. Link: https://bit.ly/3f8LPGW

19. Braga RA, Petry M, Moreira AP, Reis LP (2008) Intellwheels-a development platform for intelligent wheelchairs for disabled people. Link: https://bit.ly/3f9jOiq

20. Ganesh S, Hayter A, Kim J, Sanford J, Sprigle S, et al. (2007) Wheelchair use by veterans newly prescribed a manual wheelchair. Arch Phys Med Rehabil 88: 434-439. Link: https://bit.ly/3bIZcLP

21. Cowan RE, Nash MS, Collinger JL, Koontz AM, Boninger ML (2009) Impact of surface type, wheelchair weight, and axle position on wheelchair propulsion by novice older adults. Arch Phys Med Rehabil 90: 1076-1083. Link: https://bit.ly/3u8ANFy

22. Van der Woude LHV, Formanoy M, De Groot S (2003) Hand rim configuration effects on physical strain and technique in unimpaired subjects?. Med Eng Phys 25: 765-774. Link: https://bit.ly/3hF5kZa

\section{Discover a bigger Impact and Visibility of your article publication with}

\section{Peertechz Publications}

\section{Highlights}

* Signatory publisher of ORCID

* Signatory Publisher of DORA (San Francisco Declaration on Research Assessment)

* Articles archived in worlds' renowned service providers such as Portico, CNKI, AGRIS, TDNet, Base (Bielefeld University Library), CrossRef, Scilit, J-Gate etc.

* Journals indexed in ICMJE, SHERPA/ROMEO, Google Scholar etc.

* OAI-PMH (Open Archives Initiative Protocol for Metadata Harvesting)

* Dedicated Editorial Board for every journal

* Accurate and rapid peer-review process

* Increased citations of published articles through promotions

* Reduced timeline for article publication

Submit your articles and experience a new surge in publication services (https://www.peertechz.com/submission).

Peertechz journals wishes everlasting success in your every endeavours.

Copyright: ( 2021 Hameed S, et al. This is an open-access article distributed under the terms of the Creative Commons Attribution License, which permits unrestricted use, distribution, and reproduction in any medium, provided the original author and source are credited. 